\title{
Using creative research methods and movement to encourage reflection in children
}

\begin{abstract}
Reflection is a vital part of learning, and yet in early childhood research work on reflection is most commonly on that undertaken by teachers, and not children. This paper draws from a participatory study showing how creative research methods and somatic movement enabled 22 children aged 4-11 to reflect on their experiences and document their reflections, and reports findings for children aged 4-8. The aim of the research was to encourage the children to reflect deeply on their experiences, and to generate rich data. These data were used at the end of the study to stimulate discussion. The children demonstrated that they were able to reflect and articulate their experiences of the pressure to be right, the processes of journaling and drawing, and reflection itself. The study used a variety of methods including journaling, drawing, mark-making and modelling as part of regular sessions of somatic movement exploration and education over two years within the school day.
\end{abstract}

Keywords: creative research methods; reflection; children; journaling; embodiment; drawing

Reflective practice is seen as a vital part of education, necessary for learning (Dewey, 1933). However, it is more commonly associated with educators (Pollard, 2002) than children. This paper shares how a variety of artistic and creative research methods were used to engage young children in reflective practice, and the documentation of their process with a range of creative research methods. The study aimed to explore how children perceived and expressed their sense of embodiment through movement using sessions of somatic movement education (Leigh, 2012).

Somatic education is 'the educational field which examines the structure and function of the body as processes of lived experience, perception and consciousness' 
(Linden, 1994:1-2). It can incorporate developmental movement patterns, the emotional content present in movement, the physiology of the body and the words in which we speak of and process movement (Bainbridge-Cohen, 1993). One way of looking at somatic movement education is as a process of bringing the moving body into awareness and consciousness, becoming aware of how we feel, our breath, our emotions and grounding them in bodily sensations. This increases our embodied self-awareness, and allows us to be present, mindful and reflexive, and can be a route into developing a reflective practice (Leigh \& Bailey, 2013).

\section{Reflection and reflective practice}

There are different understandings of what reflection comprises (O'Sullivan, Tannehill, \& Hinchion, 2008; Osterman \& Kottkamp, 1993). Similar to critical thinking, it is not something that can be practised in isolation, but instead needs to be done in context. It has to be conscious, and happen in relation to an experience. By reflecting on an experience, it is possible to affect change, by perceiving it differently and changing how we react to similar experiences. Developmental research suggests that "there are age related increases in the highest degree of self-reflection" (Zelazo, 2004:12), and whilst children may be able to reflect, the level at which they can do so is determined by their developmental age, and language ability (ibid). Historically it was accepted that young children do not have the capacity to self-reflect (Flavell, 1977) and traditional research methods with them cemented that view (Robson, 2016). Children from the age of 11 have been shown to have conceptualising abilities that enable them to reflect on their experiences (Biggeri et al, 2006), and children are said to be "capable of understanding and contributing thoughtful opinions" (Biggeri, 2007:197). The importance of children's perspectives and experiences was not always valued, however the belief that children are able to reflect on experience and have a subtle understanding of them has 
meant that this is changing (Buhler-Niederberger, 2010).

Children who are given opportunities to practice reflection, increase their ability to do so (Robson, 2016). There is a symbiotic element in that having the opportunity to plan and reflect also helps foster the development of symbolic thought and the ability to represent ideas (Copple, 2003). However, teaching reflectivity is not straightforward. In order to be open to and aware of experience it is necessary to be self-aware (Brown \& Ryan, 2003). Embodied or somatic movement practices have a long history of bringing increased self-awareness and associated benefits (Lischetzke \& Eid, 2003). This increased self-awareness can then be used as a basis for learning reflective skills (Leigh \& Bailey, 2013). Reflecting on being aware of our bodies and emotions can have positive impacts on our ability to learn (Loon \& Bell, 2017). It can allow us to process relational and childhood experiences (Russell, 2016). However, what it actually means to reflect and how we go about it are not always clear. Likewise, the relationship between rumination (a negative and mal-adaptive process) and reflection can be conflated, with reflection being the desirable and adaptive form of rumination (Raes \& Hermans, 2008).

Reflection and reflective practice have become buzz words within education (Calderhead, 1989), mainly with a focus on increasing teacher or educator awareness of their practice (Parnell, 2011; Salaman et al, 2016; Zulfikar \& Mujiburrahman, 2017). One consequence of this work with adults is that reflection is largely associated with the written word. Even in studies aimed specifically at or with children, an assessment of reflective processes is made through written instruments such as questionnaires and the like (Zilka, 2017). Creative and arts based methods can instead be used to draw more specifically on the strengths of children (Blaisdell, Arnott, \& Wall, 2018). This study 
introduced young children, aged 4-11 to a variety of reflective practices, including talking, drawing, mark-making and journaling.

\section{Childhood research and creative methods}

Research activities should be fun, enjoyable and varied. Young children's brains and the ways they process information are different to adults' (Drury \& FletcherWatson, 2017). Multi-modal and visual methods are increasingly being used to understand children's experiences (Darbyshire, Macdougall, \& Schiller, 2005; Thomson, 2008). Specific methods such as 'draw, write and tell' (Angell, Alexander, \& Hunt, 2015) and the mosaic approach (Clark \& Moss, 2001) have been developed in order to capture the voices and experiences of children. An important part of these ideas is that the children need to feel that they are being listened to by the researchers, and to understand that their voices and experiences are seen as valid. Listening is an active process of communication that involves hearing, interpreting and constructing meanings (Clark, 2005). It is not limited to the spoken word, and is necessary for participation. Listening is a dynamic process that is not just the extraction of information from children. It involves them and adults discussing meanings, whilst avoiding giving the children cues or assistance (Irwin \& Johnson, 2006). Listening means not trying to guess what the children are saying (Mauthner, 1997). It includes all the different verbal and non-verbal ways in which children communicate. This is where creative research methods can be valuable, as they allow for sharing rich experiences, without exclusively relying on the spoken or written word.

Creative research methods cover a huge range of different approaches (Kara, 2015). They often incorporate arts-based methods (Leavy, 2015), and are used to 'disrupt the habitual' and elicit change and empathy (Lapum et al, 2011:102), explore identity (Gauntlett, 2007), and promote engagement and empowerment of young people 
(Lyon, 2016). Creative research methods have been described as an enabling methodology (Gauntlett \& Holzwarth, 2006). They allow those who find it hard to express themselves, and often reveal more honest and emotional stories than would be captured with more traditional methods (Brown \& Leigh, 2019). Creative methods have been widely used in research with children and young people (e.g. Clark, 2011; Coad, 2007; Darbyshire, Macdougall, \& Schiller, 2005; Harris et al, 2015). The intention of using them is to capture the voices of the children through playing to their strengths as co-researchers (Irwin \& Johnson, 2006).

\section{Method}

In order to achieve the aims of the study, children aged 4-11 took part in somatic movement exploration sessions as part of their school day over two years. The study was divided into three phases, with 22 children taking part in total. Some children took part over the whole time, and others only participated for one phase over an academic term. The frequency of sessions varied in each phase, up to once a week over an academic year. The children were mostly in mixed year class groupings. For a detailed description of the phases, groupings and content of the sessions see Leigh (2012). In general the content of the sessions was derived from a mix of the embodied or somatic movement forms in which I have experience; primarily yoga (Pattabhi Jois, 1999), Authentic Movement (Adler, 2002) and Integrative Bodywork and Movement Therapy (Hartley, 1989). Similar movement programmes have been shown to reduce cortisol levels and improve emotion recognition in children (Stueck et al, 2016) and to be of value for children with emotional and behavioural difficulties (Cullen-Powell \& Barlow, 1995).

The research methodology was in keeping with the phenomenological tradition that 'has taken a step on the path towards an ontology which combines the mind and the 
body' (Alerby, 2003:18). Phenomenology is a form of enquiry used to study human activities and experiences (Leder, 1990; Merleau-Ponty, 2002). Phenomenological approaches urge researchers to 'listen and understand...collaboratively' (Todorova, 2011:37). As such, it aligns with the ethos and approach of somatic education.

The methodology was designed to be enjoyable, and to ensure that the children were recognised as the real experts of their lives (Pearce \& Bailey, 2010). The emphasis throughout was that the children's own perceptions were valuable, and that there were no 'right' answers (Punch, 2002), however, as will be seen in the findings, some of the children struggled with this aspect.

In each session the children were given time and space to explore their own sense of being embodied and what they were experiencing. They were given specific instructions and tasks designed to help them learn how to reflect and think about what they were feeling and how and where they felt it. For example, in a session exploring emotions, they might be asked to show me what happy looked like, and then reflect on where they felt that within their body, what it felt like, and what they imagined when they were feeling it. They were encouraged to use art materials throughout the sessions, and share with their peers at appropriate times. In every session each child had time and space to journal, mark-make or draw either at designated points or throughout the session. In order to minimise issues of conflict over materials, I ensured that all the children had access to pencils, oil pastels and high-quality paper. The quality of the materials was important, as it differentiated the work from that of 'ordinary' class materials and encouraged them to participate (Coad, 2007). Drawing and mark-making were used as an 'avenue for young children to express their views and experiences' (Clark, 2005). The act of creating a drawing can be seen as a process of learning and research (Hay \& Pitchford, 2016). These methods provided a way of allowing the 
children to reflect, to express themselves and allow their experiences and voices to be heard.

\section{Ethical considerations}

Ethical considerations are extremely important when working with children (Einarsdottir, 2007). Participatory research of this kind has its own particular ethical issues as young children are used to doing what they are told by adults, particularly in an educational context (Punch, 2002). Throughout the study I followed the professional and ethical guidelines of my professional bodies (BWoY, ISMETA), ensuring that I had full insurance, and attended regular supervision sessions.

A full ethical approval process through the University Research Ethics Committee was completed before the sessions started. Gaining consent on behalf of and assent from children has its own considerations (Jago \& Bailey, 2001). There is an implicit compulsion that the children and their parents will assent to participation as the sessions took place within a school day. For this study written consent was gained from the school governors, the parents of the children at the beginning of each research phase, and verbal assent and consent from the children on an on-going basis. I told the children that their drawings, photographs, marks or words were to help me understand what they thought and experienced, and that everything they did was important. They knew that I would use their work in my own work, and that it would be shared with other people interested in what they experienced and thought, but that they would not be identified (even though some wanted to be!).

\section{Data and analysis}

The data included observational field notes, drawings, journaling and mark-making, photographs of and by the children from the sessions, my reflective journal and 
interviews with some of the children after the end of the study. The data were collected and analysed from a participatory and phenomenological perspective. This means that the children's own perceptions and experiences were foregrounded. The themes reported here arose from their words and thoughts as they reflected on their own reflections. The findings are in narrative form, and include verbatim quotes from the children, and some of the images created. When it came to analysis of the drawings, they were considered as artefacts in their own right (Latour, 1999) as well as a mode of or stimulus for reflection, and were analysed for the hidden contours of material sense and affective feeling. The interviews were analysed in part using the qualitative software package NVivo. The data were also analysed by hand, which practically resulted in sifting ever-changing piles of drawings, images, highlighted text and models. This allowed for the 'analytic imagination' which lies at the heart of the craft of interpreting data (James, 2012). All quotations have been anonymised.

\section{Findings}

This paper is focused on understanding how the children learned to reflect and generated rich data detailing their experiences through a variety of creative methods. The findings have been organised into four broad themes; the idea of getting things right, the experiences of journaling and drawing in the sessions, and lastly the experience of reflecting on their reflections.

\section{'Getting it right'}

Throughout the study I emphasised to the children that there were no wrong or right answers to the questions I asked. We shared 'circle' time in every session, where everyone had an opportunity to move or speak, and their contribution, no matter what it was, would be applauded. This ethos of acceptance and non-judgement is fundamental 
to person-centred therapeutic approaches (Rogers, 1967) and early years approaches such as Reggio Emilia, and is seen as vital in encouraging children to reflect (Copple, 2003). This created a feeling of celebration and acceptance. However, the issue of 'getting it right', and the impact of a child's need or desire to please an adult remained a consideration. It was spoken of by one child when she came to talk about her experiences.

'I felt excited and nervous and I thought that I could get it right or I could get it wrong'. (E age 7)

After further questioning, and mostly with reference to drawing, which was what she had remembered doing most, E said 'I thought it was right when I had to draw my face...I thought it was going to be wrong when I didn't draw my body right'. This ties in to the idea that children who do not perceive themselves to be good at drawing will feel constrained when asked to draw (Buckingham, 2009). The children were never told to draw anything in particular, instead they were offered materials and told they could use them how they wanted. E. was the only child that mentioned that she thought that there was a need to do things right, though she may not have been the only child who felt that way. In contrast, many children spoke of the freedom that they had to choose, say, or draw what they wanted.

'It's pretty fun because you do whatever you want, no-one can tell you what to do and that, you can do whatever you want to do, really.' (C. age 6)

It seemed that the majority of the children were assured that their experiences were valid, and accepted.

I was present in the children's environment over two years. As such, I could be seen to have 'trusted adult' status. This allowed the children to explore the work and 
express themselves freely, maybe more so than they would with an 'unknown adult' (Irwin \& Johnson, 2006). I needed to allow the students to trust me enough to say what they felt and thought, and not what they thought was the 'right' answer or what I wanted to hear. The children's reflections showed that the effort I took to reinforce their own authority went a long way towards achieving this, that their experiences, thoughts and feelings were valid.

\section{Journaling}

The journaling within the sessions combined writing and drawing, and the children were given time to journal without direction. Some chose to describe their movement, or how they felt when they moved, or stayed still. I noted 'some of the children (particularly the older ones) are very willing to participate in the 'journaling' aspect of exploring themes, their feelings, thoughts and movement through writing and art' (Field Notes). However, the youngest children also chose to write descriptively, either annotating their drawings, or as journal entries. For example, P., age 4, described his movement in words 'I spin a round (sic)'. D., age 6, chose to draw a picture of himself balancing, and wrote how he felt when he balanced, 'It's quit esey and some timse its quit hard (sic).' This shows the children were using language (in addition to drawings) to shape their reflections (Zelazo, 2004).

The children were encouraged to write about how they felt in addition to describing movement as part of a process of gaining awareness about their state of mind and physical self. This included stating how easy or hard they found aspects of the work. Becoming aware of their state of mind, and beginning the process of reflecting on it, allowed them the choice of changing that state. Awareness and acceptance are necessary precursors to change within the framework of somatic movement education 
(Hartley, 1989). The participants were using words and pictures to describe their embodied experiences and to thus place verbal definitions on them (Pink, 2009).

Although this aspect of the work was most eagerly accepted by the oldest participants, some of the younger children also enjoyed journaling. One girl, aged 4 at the beginning of the sessions, and 6 by the end, said the following in her interview about journaling and communicating about and around the work.

\footnotetext{
'That was fun because you really get to explain your feelings and stuff....And, sometimes it's really hard to talk about your feelings, so it's easier just to write them down, because you can- when you write it down you can rub it out and do it again if you don't think that's right, but when you're talking, you're saying no, butwell, yes. They know you've already said it....Well, again it's hard, sometimes it's hard to say, like I felt like this, because feelings are very complex, but it's also nice to share with other people how you feel.' (S. age 6)
}

The ability this young girl had to elucidate on what it meant to be able to express herself on paper and to take the time to reflect on her words to ensure that she was writing and communicating exactly what she meant to, demonstrated that she was using the process to reflect on her experiences. She also commented on how the medium in which reflections are shared alters the experience of sharing. There is a difference in reflecting with others (i.e. talking through the process of reflection) and sharing thoughts already gathered together in the form of writing.

Journaling has been used as a technique to help build rapport with older children during interviews (Spratling, Coke, \& Minick, 2012), and to increase the emotional intelligence of early-years teachers (Kremenitzer, 2005). Journaling often forms part of reflective or reflexive practices for health practitioners, educators and therapists. As adults it can allow us to process and work through experiences from our childhood 
(Russell, 2016). These data show that children as young as 4 are able to use language and forms of journaling in order to reflect on and process their experiences.

\section{Drawing}

Drawing definitely appealed to some of the children. The lack of emphasis on language allowed those who were younger, or those more comfortable expressing themselves creatively, to take part and to reflect on their experiences (Driessnack, 2005). We know that children as young as 3 are able to understand, recognise and express emotions through drawings (Misailidi \& Bonoti, 2008). Art has a history of being used therapeutically (Cox et al, 2010) and as a method of reflexivity (Lahman et al, 2010). Artistic representations can be used to increase empathy (Lapum et al, 2011). Young people who perceive themselves to be 'good' at drawing or art may be attracted to using these media (Lyon, 2016).

One 8-year-old girl drew the following after a session on emotions and how we move and feel them in our bodies. She used imagery of weather, and vivid colours to express how she felt as emotions moved through her body. The colours are strikingly bold, with the use of red inside her body, and large bold yellow zigzags of lightening above a grey cloud and blue dashes of rain. She drew her features, her hair and eyes, in heavily and her arms are raised almost hiding her face, as though she is hiding from the violence of her emotional storm.

[insert Figure 1 here]

In the interviews, the children were shown their drawings and artifacts to stimulate discussion. Similar processes have been used with interviews allowing children to share the meanings of their drawings (Mizen \& Ofusu-Kusi, 2010). M. spoke about drawing 
in the sessions as she reflected on the work over the previous year. At the time of the interview M. was 6 years old, although for much of the work she had been 4 or 5 . This extract came at the end of the interview, after we had talked about writing and drawing and how it felt to move.

'Me: Do you think looking back and remembering all of those months ago what you would have liked to have done more of?

M.: More pictures.

Me:More pictures. Do you like drawing pictures? Do you like drawing pictures about moving and what it feels like to move?

M.: Yeah.

Me:Why do you like drawing pictures like that?

M.: Because it's fun doing that.

Me: Why is it fun drawing?

M.: Because it's all colourful and I like colouring in the picture...

Me: Okay, so when you draw pictures of you how you feel when you move, you

like drawing them all colourful?

M: Yes.

Me:Is that how you feel when you move?

M.: Yes.

Me:You feel colourful when you move?

M.: Yes.' (M. age 6)

The association of colour with movement by M., may have been triggered by the use of vibrant oil pastels to draw within the sessions, or conversely, she may have expressed her enjoyment of using colours because of her internal experience of moving.

The children in the study were able to use the art materials and the non-directed time to journal or draw in order to reflect on their experiences and process the emotional work from the sessions. For some, the space and opportunity to express themselves in this way stood out as one of the highlights of their participation in the sessions. The drawings created varied from annotated figures describing movement and thoughts, to 
evocative images and artefacts. This variation shows the ways they processed their experiences, and how they used drawing in different ways to model and express themselves (Hay \& Pitchford, 2016).

\section{Reflecting on reflection}

Few studies include child participants at the data analysis stages (Pinter \& Zandian, 2015). In this study, the children were invited to reflect on their experiences. Their own drawings, journals and the like were used as adjuncts to interviews, to stimulate the conversation and prompt them to explore their own meaning making. This allowed the children to express how they felt about the process of reflecting as well as the experience of participating in the sessions.

I asked all the children how they felt about being asked to communicate and reflect through writing and drawing - they reflected on what it felt like, and how it was to look back on work from when they were younger, sharing how the reflection made them feel. Many of the children said that it was important to share how they felt with others. Reflection was not a self-absorbed activity, but one that gained more meaning in context of the relationships of those around them. The children spoke about how practice and experience of reflecting through journaling and drawing made the process easier over time, and this idea is echoed by Robson (2016). Familiarity with the concept may have allowed the children to gain some of the positive benefits of an embodied reflective practice, similar to those experienced by practitioners (Smears, 2009). It must be considered, however, that over the time of the study all the children grew older and matured developmentally, and this was another reason why the reflective process became easier (Zelazo, 2004).

Writing and drawing were not the only way that the children were able to communicate their experiences of embodiment. The children's reflections through 
journaling, speaking, drawing and moving showed that they used their embodied selfawareness to make sense of what they were experiencing and feeling, and their reflections on these reflections show clearly that even the youngest children were aware of what they were doing and how it made them feel to have time and space to reflect.

\section{Discussion}

Given the developmental nature of self-reflection in childhood (Zelazo, 2004), the challenges around teaching reflection (Leigh \& Bailey, 2013) and the need for children to practice in order to improve at it (Robson, 2016), researchers must be careful that they do not make assumptions about a child's capabilities. We need to be clear about the assumptions we make about childhood that inform our approach, methods and data analysis. Children are not mini-adults, and should not be treated as such. They have their own competencies, and it is possible to develop innovative and adaptive methods that play to their strengths (Fargas-Malet, 2010). Research methods that position children as active agents such as the participatory methods shown here, tend to orientate themselves to the strengths of children and draw out their voices and experiences whilst capturing their individual views (Harris et al, 2015). By choosing research methods carefully, we may be able to negate the impetus children feel to 'get things right'. However, children may be vulnerable to suggestibility and influenced by the status of the researcher (Greene \& Hogan, 2005). This may be particularly evident if the children perceive the researcher to have the role of or equivalent to a teacher as in this study (Greig \& Taylor, 1999). Ideally, prior to the start of a project one would develop rapport, and gain trust to allow a fuller disclosure of information (Irwin \& Johnson, 2006). In this study I had formed a relationship with the school over several years. My presence could be interpreted as one of authority which may have affected the children's perceptions (Pearce \& Bailey, 2011). They may have felt pressure to 'say 
what they think adults want them to say' (Fargas-Malet et al, 2010).

Using creative methods facilitated this study on several levels. The use of journaling and drawing (among other methods) allowed the children to truly participate within the research and know that their voices were heard and valued even when they struggled to speak or write words that expressed their thoughts. The multi-modal approach ensured there was a mode of communication open to them, be it through sharing with their peers, taking photographs, drawing, talking, or writing. This helped them to process and record their experiences, aiding their development of embodied self-awareness, maintaining a sense of fun and play and enjoyment. As a means of research, it generated a varied and rich range of data that allowed me to document and analyse their experiences. The creative approach facilitated not only the process of developing self-awareness, but also the process of reflection

This paper shows how children as young as 4 were able to use these creative approaches to help them reflect on their experiences. The examples given show how children reflected in sessions of somatic movement, and then reflected on those reflections - reflecting about the very process of reflection. The sessions were designed to enhance their expression of their sense of embodiment. They were invited to increase their embodied self-awareness and to become more mindful about themselves, about how they perceived and experienced their inner self and the workings of their body, about how they moved through and interacted with the world around them.

Reflection was a part of that process, and fed into that process. The children demonstrated clearly that they were able to reflect through the ways in which they journaled, drew and spoke about their experiences within and then after the sessions. Reflection was an integral component of increasing embodied self-awareness. They were given time and space to reflect in every session. They did this through sharing in a 
group and individually by way of writing, drawing, model making and talking. The children reflected on the elements that they wanted to share. In the interviews they were given the chance to look back through their work and reflect on their experiences as a whole. The children appeared to develop their ability to reflect, be mindful, and express what they were reflecting on in an embodied way over time. They appeared to gain insight into their embodied experience. That is they used their embodied self-awareness linked in with their ability to reflect on emotions, experiences and events in their lives.

Previous work from this study showed how the children began to be aware of how they felt when they moved, physically and emotionally (Leigh, 2017). They were able to express and share these feelings and articulate them, as well as show empathy towards others based on seen movements and expressions, for example by being careful of how others might be feeling, and how their own actions might impact on their peers (ibid). This mindful awareness increased the amount of data they had available to reflect on and process, introducing them to a form of embodied reflective practice (Leigh \& Bailey, 2013). By remaining open not only to their own interpretation of the world, but also those of others, they were more able to be aware of the perspectives of others, increase their empathy (Cromby, 2011; Sheets-Johnstone, 2010) and to become more aware of and self-regulate their emotions (Leigh, 2017).

Journaling, mark-making and speaking, drawing and moving may have allowed the children to begin to develop a reflective practice (Punch, 2002). Through these reflective practices they were able to show how they used their embodied selfawareness to make sense of what they were experiencing and feeling. The children were able to reflect on the experience of reflecting and the value that it had for them. Although the oldest children appeared to journal and write most frequently, even the youngest ones in the study seemed able to reflect on and express their experiences. The 
children demonstrated that they were able to use the sense of embodied self-awareness developed within the movement sessions to reflect on their emotions, their experiences and even the process of reflecting. The creative approach not only allowed the children to generate rich data that expressed their experiences, but also helped to facilitate their ability to reflect on, process, and learn from their experiences.

\section{Works Cited}

Adler, J. (2002). Offering from the Conscious Body The Discipline of Authentic Movement. Rochester, Vermont: Inner Traditions.

Alerby, E. (2003). 'During the break we have fun': a study concerning pupils' experience of school. Educational Research, 45(1);17-28.

Angell, C., Alexander, J., \& Hunt, J. (2015). 'Draw, write and tell': A literature review and methodological development on the 'draw and wrote' research method. Journal of Early Childhood Research, 13(1);17-28.

Bainbridge-Cohen, B. (1993). Sensing, Feeling and Action. Northampton, MA: Contact Editions.

Biggeri, M. (2007). Children's valued capabilities. In M. Walker, \& E. Unterhalter (Eds.), Amartya Sen's capability approach and social jusitice in education (pp. 197-214). New York, NY: Palgrave Macmillan.

Biggeri, M., Libanora, R., Mariani, S., \& Menchini, L. (2006). Children conceptualizing their capabilities: Results of a survey conducted during the first children's world congress on child labour. Journal of Human Development, 7(1);59-83.

Blaisdell, C., Arnott, L., \& Wall, K. (2018). Look who's talking: Using creative, playful arts-based methods in research with young children. Early Childhood Research, 1-18. 
Brown, K. W., \& Ryan, R. (2003). The Benefits of Being Present: Mindfulnes and Its Role in Psychological Well-Being. Journal of Personality and Social Psychology, 84(4);822-848.

Brown, N., \& Leigh, J. (2019). Creativity and playfulness in higher education research. In M. Tight, \& J. Huisman (Eds.), Theory and method in higher education research: Volume 4 (pp. 49-66). Bingley: Emerald.

Buckingham, D. (2009). 'Creative' visual methods in media research: possibilities, problems and proposals. Media, Culture \& Society, 31(4);633-652.

Buhler-Niederberger, D. (2010). Childhood sociology - defining the state of the art and ensuring reflection. Current Sociology, 58(2);155-164.

BWoY. (2017). British Wheel of Yoga About us. Retrieved from British Wheel of Yoga: https://www.bwy.org.uk/about/

Calderhead, J. (1989). Reflective Teaching and Teacher Education. Teaching and Teacher Education, 5(1);43-51.

Clark, A. (2011). Multimodal map making with young children: exploring ethnographic and participatory methods. Qualitative Research, 11(3);311-330.

Clark, A., \& Moss, P. (2001). Listening to Young Children: The Mosaic Approach. London: National Children's Bureau for the Joseph Rowntree Foundation.

Clark, A., \& Moss, P. (2005). Spaces to Play more listening to young children using the Mosaic approach. London: National Children's Bureau.

Coad, J. (2007). Using art-based techniques in engaging children and young people in health care consultations and/or research. Journal of Research in Nursing, $12(5) ; 487-497$.

Copple, C. (2003). Fostering young children's representation, planning, and reflection: A focus in three current early childhood models. Applied Developmental Psychology, 24;763-71. 
Cox, S., Lafreniere, D., Brett-MacLean, P., Collie, K., Cooley, N., Dunbrack, J., \& Frager, G. (2010). Tipping the iceberg? The state of arts and health in Canada. Arts \& Health, 2(2);109-124.

Cromby, J. (2011). Affecting Qualitative Health Psychology. Health Psychology Review, 5(1);79-96.

Cullen-Powell, L., \& Barlow, J. (1995). Promoting inner stillness: the value of a selfdiscovery programme for children with social, emotional and behavioural difficulties. British Journal of Special Education, 32(3);137-143.

Darbyshire, P., Macdougall, C., \& Schiller, W. (2005). Multiple methods in qualitative research with children: more insight or just more? Qualitative Research, $5(4) ; 417-436$.

Dewey, J. (1933). How We Think: A Restatement of the Relation of Reflective Thinking to the Educative Process. (A. Pollard, Ed.) Boston: D.C. Heath.

Driessnack, M. (2005). Children's Drawings as Facilitators of Communication: A MetaAnalysis. Journal of Pediatric Nursing, 20(6);415-423.

Drury, R., \& Fletcher-Watson, B. (2017). The infant audience: The impact and implications of child development research on performing arts practice for hte very young. Journal of Early Childhood Research, 15(3);292-304.

Einarsdottir, J. (2007). Research with children: methodological and ethical challenges. European Early Childhood Education Research Journal, 15(2);197-211.

Fargas-Malet, M., McSherry, D., Larkin, E., \& Robinson, C. (2010). Research with children: methodological issues and innovative techniques. Journal of Early Childhood Research, 8(2);175-192.

Flavell, J. (1977). Cognitive development. Englewood Cliffs: Prentice Hall.

Gauntlett, D. (2007). Creative explorations: New approaches to identities and audiences. Abingdon: Routledge.

Gauntlett, D., \& Holzwarth, P. (2006). Creative and visual methods for exploring identities. Visual Studies, 21(1);82-91. 
Greene, S., \& Hogan, D. (Eds.). (2005). Researching Children's Experience: Approaches and Methods. London: Sage.

Greig, A., \& Taylor, J. (1999). Doing Research with Children. London: Sage.

Harris, C., Jackson, L., Mayblin, L., Piekut, A., \& Valentine, G. (2015). 'Big Brother welcomes you': exploring innovative methods for research with children and young people outside of the home and school environments. Qualitative Research, 15(5);583-599.

Hartley, L. (1989). Wisdom of the Body Moving. Berkeley, CA: North Atlantic Books.

Hay, D., \& Pitchford. (2016). Curating blood: How students' and researchers' drawings bring potential phenomena to light. International Journal of Science Education, 38(17);2596-2620.

Irwin, L., \& Johnson, J. (2006). Interviewing Young Children: Expicating Our Practices and Dilemmas. Qualitative Health Research, 15(6);821-831.

ISMETA. (2017). ISMETA about ISMETA. Retrieved from ISMETA: https://ismeta.org/about-ismeta

Jago, R., \& Bailey, R. (2001). Ethics and paediatric exercise science: Issues and making a submission to a local ethics and research committee. Journal of Sports Sciences, 19(7);527-535.

James, A. (2012). Seeking the analytic imagination: reflections on the process of interpreting qualitative data. Qualitative Research, 13(5);562-577.

Kara, H. (2015). Creative research methods in the social sciences: A practical guide. Bristol: Policy Press.

Kremenitzer, J. P. (2005). The emotionally intelligent early childhood educator: selfreflective journalling. Early Childhood Education Journal, 33(1);3-9.

Lahman, M., Geist, M., Rodriguez, K., Graglia, P., Richard, V., \& Schendel, R. (2010). Poking around poetically: Research, poetry, and trustworthiness. Qualitative Inquiry, 16(1);39-48. 
Lapum, J., Ruttonsha, P., Church, K., Yau, T., \& David, A. M. (2011). Employing the arts in research as an analytical tool and dissemination method: interpreting experience through the asthetic. Qualitative Inquiry, 18(1);100-115.

Latour, B. (1999). Pandora's hope: Essays on the reality of science studies. Cambridge, MA: Harvard University Press.

Leavy, P. (2015). Method meets art: Arts-based research practice. New York, NY: Guildford Press.

Leder, D. (1990). The Absent Body. Chicago, IL: University of Chicago Press.

Leigh, J. (2012). Somatic movement and education: a phenomenological study of young children's perceptions, expressions and reflections of embodiment through movement. Ph.D. Thesis, University of Birmingham.

Leigh, J. (2017). Experiencing emotion: Children's perceptions, reflections and selfregulation. Body, Movement and Dance in Psychotherapy, 12(2);128-144.

Leigh, J., \& Bailey, R. (2013). Reflection, Reflective Practice and Embodied Reflective Practice. Body, Movement and Dance in Psychotherapy, 8(3);160-171.

Linden, P. (1994). Somatic Literacy: Bringing Somatic Education into Physical Education. Journal of Physical Education, Recreation and Dance, 64.

Lischetzke, T., \& Eid, M. (2003). Is Attention to Feelings Beneficial or Detrimental to Affective Well-Being? Mood Regulation as a Moderator Variable. Emotion, 3(4);361-77.

Loon, M., \& Bell, R. (2017). The moderating effects of emotions on cognitive skills. Journal of Further and Higher Education. doi:10.1080/0309877X.207.311992

Lyon, D. (2016). Researching young people's orientations to the future: the methodological challenges of using arts practice. Qualitativce Research, $16(4) ; 430-445$.

Mauthner, M. (1997). Methodological Aspects of Collecting Data from Children: Lessons from Three Research Projects. Children and Society, 11;16-28. 
Merleau-Ponty, M. (2002). Phenomenology of Perception. (C. Smith, Trans.) Oxon: Routledge.

Misailidi, P., \& Bonoti, F. (2008). Emotion in children's art: Do young children understand the emotions expressed in other children's drawings? Journal of Early Childhood Research, 6(2);189-200.

Mizen, P., \& Ofusu-Kusi, Y. (2010). Unofficial truths and everyday insights: understanding voice in visual research with the children of Accra's urban poor. Visual Studies, 25(3);255-267.

Oliver, K., \& Lalik, R. (2001). The body as curriculum: learning with adolescent girls. Journal of Curriculum Studies, 33(3);303-333.

Osterman, K., \& Kottkamp, P. (1993). Reflective practice for educators: Improving schooling through professional development. Newbury Pak, CA: Corwin Press, Inc.

O'Sullivan, M., Tannehill, D., \& Hinchion, C. (2008). Teaching as Professional Enquiry. Limerick: University of Limerick.

Parnell, W. (2011). Experiences of teacher reflection: Reggio inspired practices in the studio. Journal of Early Childhood Research, 10(2);117-133.

Pattabhi Jois, S. K. (1999). Yoga Mala. New York: North Point Press.

Pearce, G., \& Bailey, R. P. (2010). Football Pitches and Barbie Dolls: young childrens' perceptions of their school playground.

Pink, S. (2009). Doing Sensory Ethnography. London: Sage.

Pinter, A., \& Zandian, S. (2015). 'I thought it would be tiny little one phrase that we said, in a huge pile of papers': children's reflections on their involvement in participatory research. Qualitative Research, 15(2);235-250.

Pollard, A. (Ed.). (2002). Readings for Reflective Teaching. London: Continuum.

Punch, S. (2002). Research with children: the same or different from research with adults? Childhood, 9(3);321-341. 
Raes, F., \& Hermans, D. (2008). On the mediating role of subtypes of rumination in the relationship between childhood emotional abuse and depressed mood: Brooding versus reflection. Depression and Anxiety, 25;1067-70.

Robson, S. (2016). Are there differences between children's display of self-regulation and metacognition when engaged in an activity and when later reflecting on it? The complementary roles of observation and reflective dialogue. Early Years: An International Research Journal, 36(2);179-94.

Rogers, C. A. (1967). A therapist's view of psychotherapy. London: Constable.

Russell, L. (2016). Reflexive encounters with embodied resistance to relational forgiveness. Reflective Practice: International and Multidisciplinary Perspectives. doi:10.1080/14623943.2016.1265494

Salaman, A., Sumison, J., Press, F., \& Harrison, L. (2016). Implicit theories and naive beliefs: Using the theory of practcie architectures to deconstruct the practices of early childhood educators. Journal of Early Childhood Research, 14(4);431-443.

Sheets-Johnstone, M. (2010). Kinesthetic experience: understanding movement inside and out. Body, Movement and Dance in Psychotherapy, 5(2);111-127.

Smears, E. (2009). Breaking old habits: professional development through an embodied approach to reflective practice. Journal of Dance and Somatic Practices, 1(1);99-110.

Spratling, R., Coke, S., \& Minick, P. (2012). Qualitative data collection with children. Applied Nursing Research, 25;47-53.

Stueck, M., Villegas, A., Lahn, F., Bauer, K., Tofts, P., \& Sack, U. (2016). Biodanza for kindergarten children (TANZPRO-Biodanza): reporting on changes of cortisol levels and emotion recognition. Body, Movement and Dance in Psychotherapy, 11(1);75-89.

Thomson, P. (2008). Children and young people: Voices in visual research. In P. Thomson (Ed.), Doing visual research with children and young people (pp. 119). London: Routledge. 
Todorova, I. (2011). Explorations with interpretative phenomenological analysis in different socio-cultural contexts. Health Psychology Review, 5(1);34-38.

Zelazo, P. (2004). The development of concious control in childhood. TRENDS in Cognitive Sciences, 8(1);12-17.

Zilka, G. (2017). Awareness of ICT capabilities, digital literacy, and use of reflective processes in children who received their first home computer. International Journal of Technology Enhanced Learning, 9(1);80-98.

Zulfikar, T., \& Mujiburrahman. (2017). Understanding own teaching: Becoming reflective teachers through reflective journals. Reflective Practice: International and Multidisciplinary Perspectives. doi:10.1080/4623943.207.1295933

\section{Figures}

Figure 1 'How We Move And Feel Emotion' 